\title{
Conceptual basis of using digital technologies for reducing transport costs in product price
}

\author{
Elena Palkina ${ }^{1, *}$ \\ ${ }^{1}$ State Marine Technical University, St. Petersburg, Russia
}

\begin{abstract}
The article presents the conceptual foundation of integrated management of digital transformation processes in transport which plays an important role in support of industrial production and determines the prices of products. The paper substantiates the interrelated use of the following concepts in building the integrated management system for digital transport: Industry 4.0, process management, sustainable development, stakeholder influence, value-based management, lean production and risk management. Improving the theoretical basis of the digital transformation management system in transport will allow industrial enterprises to improve the efficiency of their activity, taking into account the expectations of stakeholders. Examples of practical implementation of conceptual provisions are presented. The author suggests to use the specific key performance indicators that allow to evaluate the effectiveness of the proposed integrated management system for digital transport systems based on the considered concepts. The achieved results form the scientific basis for elaboration and implementation of the economic mechanism for ensuring sustainable increasing efficiency of transport organizations, serving the industrial production and determining distribution costs in conditions of the digital economy.
\end{abstract}

\section{Introduction}

Transport plays an important role in support of industrial business and substantially determines the prices of products. It is an essential link in technological chain of goods production. Providing material flows of various production resources, intermediate and final industrial product at all stages of its manufacturing, transport acts as an integrator of production activities of enterprises in different branches of economy. A significant share of transport operations is an integral part of production processes for the delivery of raw materials, machinery and equipment (including imported) to the manufacturing companies, and also delivery of goods to consumers, including for export etc. So, manufacturing industry is characterized not only by high transport capacity, but also by a wide variety of transportations. In connection with the above, one of the ways to improve the efficiency of transport services for industrial production is to improve the organization and technology of transportation using modern, including specialized, vehicles, which will increase the productivity of transport facilities and, as a result, reduce the transport costs for

\footnotetext{
*Corresponding author: elena_palkina@hotmail.com
} 
manufacturers. According to experts, the transport costs in supply, production and distribution processes are currently on average up to one third of the price of the final product. By the way, for some types of cargo, produced in Russia and intended for export, the transport component reaches $60-70 \%$ [1]. Increasing the competitiveness of Russian products on the world market makes it necessary to reduce costs including by minimizing the transport component in the price of products. In accordance with the above, the purpose of this article is to develop the conceptual foundation of integrated management system of digital transformation processes in transport in order to reduce transport costs in the product price.

\section{Materials and Methods}

At the present time the main factor determining the competitiveness of national economy in the world market is the speed of production and circulation processes. In modern conditions of total digitalization, automation of processes, the success of companies is mainly determined by their rapid flexibility and high speed of reaction in developed competitive markets. So, if a product can be ordered and paid for simultaneously via the Internet, then one of the important factors in making a decision by the consumer is the speed of its delivery. In addition, speeding up the transportation of goods and passengers leads not only to increased customer satisfaction, but also to lower costs and, as a result, the final cost of goods and services, which increases their profitability and competitiveness. Therefore, in modern digital world, the role of transport in the socio-economic development of the country is significantly increasing.

The global trend of digitalization of the economy, which is one of the important priorities of the Russian Federation in the context of the development of the information society [2], also affected the transport sector. The trajectory of innovative development of transport systems assumes, in particular, the using of unmanned vehicle management technologies, modern information and communication technologies, specialized means of fixing and analyzing geolocation, video surveillance, and artificial intelligence. The usage of modern digital technologies for organizing the transportation process, which provide for the full integration of intelligent communication technologies between the user, the vehicle, the traffic management system and the infrastructure, in Russia contributes to ensuring the sustainable competitiveness of domestic companies in the transport services global market, forms the basis of multimodal high-speed transport in a new transport communications system, and becomes an impulse for creating large multimodal hubs of international importance, providing interconnection of traffic schedules of different types of transport using a unified information system, offering new online services, which in general will contribute to the convenience of consumers, getting transport services.

At the same time, there is a certain discreteness, inconsistency of processes and phenomena in the digitization of transport systems, which reduces the effectiveness of digital transformation of transport and can lead to increased costs, and, as a consequence, to reducing the competitiveness of domestic products in the world market. The results of the analysis of domestic and foreign literature indicate insufficient degree of elaboration of the theoretical and conceptual provisions for developing transport system management in the digital economy [3-18]. It is also important to note the lack of justification of the need to apply certain management concepts for organizations of transport industry in the specialized literature. In this connection, in order to solve the problem of increasing the effectiveness of transport organizations' activities, which is associated with the process of digital transformation of transport, it is necessary to form a conceptual basis for building an adequate system for managing digitalization in transport. 
The solution of the identified problem was based on the use of dialectical approach to the study of socio-economic processes, methods of comparison, analysis, synthesis, generalization, grouping, and expert assessments.

\section{Results}

The basic provisions of the concepts of stakeholders, Industry 4.0, process management, sustainable development, value-based management, lean production and risk management, and also system approach to management have made the scientific basis of the research (see Fig. 1).

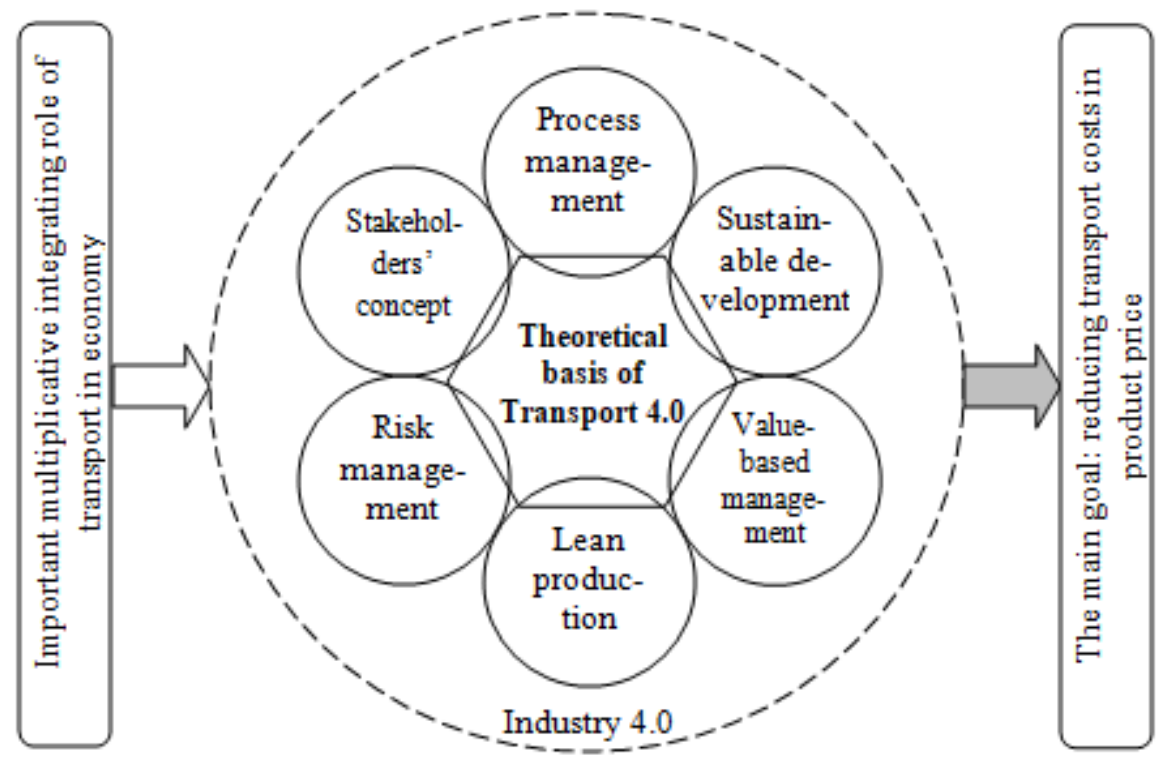

Fig. 1. Synthesis of the basic concepts - the intelligent core of Transport 4.0.

Building digital transport systems in terms of improving the efficiency of their functioning for the economy, society, and environment, in our opinion, should be based on the consolidation of theoretical and methodological provisions of the next modern concepts: Industry 4.0, sustainable development, process management, lean production, value-based management, the concepts of stakeholders, and risk management, which form the basis of the integrated management system.

The concept Industry 4.0 provides end-to-end digitization of all physical assets and their integration into the digital ecosystem together with business partners involved in the value chain. Even today, driverless transport, motion sensors, smart contracts, distributed registry technologies (blockchain), and big data are widely used in transport. Thus, the use of blockchain allows to store arrays of information about the rendered transport services, operation, repairs of vehicles, manage the transport process in real time, while ensuring its transparency and increasing the efficiency of operations. In addition, blockchain is the technological basis for smart contracts, which provide for the implementation of a mechanism for the programmable and sequential execution of contracts conditions. The use of Big Data technology in the transport industry allows for optimization of transport flows, high throughput of transport infrastructure, efficient use of resources by collecting, processing and analyzing data on the movement, technical condition of vehicles, etc. The introduction of the Internet of things in the activities of transport companies also makes it 
possible to increase the efficiency of resource use and make rational management decisions based on the data obtained from remote control and real-time monitoring systems. In addition, thanks to the ability to visualize and evaluate ongoing processes in real time, augmented and virtual reality technologies are becoming one of the defining trends in the construction of intelligent transport systems.

Sustainable development concept can be presented in the form of the triad of the terms "efficiency - environmentally friendly - social significance" and involves ensuring balanced socio-economic development with environmental protection. This concept is also implemented in transport, e.g. in the development and production of new environmentally friendly types of "green" transport, such as magnetolevitation, electric vehicles, etc.

The concept of value-based management defines the dominant criterion for management decisions that ensure the process of digital transformation of transport systems - increasing value of organizations, and forms the basis for identifying key growth drivers. The key indicator of changes in the company's value is the economic value added. It should be noted that cost savings due to the implementation of digital technologies in transport lead to the increasing in operating profit before interest and taxes and to decreasing in invested capital (mainly due to increased asset productivity), which means an increase in economic value added and value of a firm.

The concept of process management allows to improve quality of transport services while saving resources, coordination of interaction with contractors, economically justified reduction of the level of prices for transportation and thereby increase customer satisfaction and competitiveness of transport organizations, increase sales and business value by reducing the time of operations, eliminating duplicate and outdated operations. One of the key features of transport is that transport services do not exist in the form of an independent material product, but are a continuation of the reproduction process of other sectors of the economy, an element of the value-added chain of commodity products. Thus, the delivery time, quality and price of transport services are important. In this regard, the best approach is a process approach to management that involves quality control and assessment of the economic value added of each operation. At the same time, the reproduction process in transport has a modified structure that differs from other sectors of the economy, namely: consumption and implementation of specific transport work are combined with the process of transport production. The key business processes from the point of view of creating economic added value of transport organizations are: acceptance and execution of an application for transportation from a client, promotion of new services, rolling stock provision etc. Using of digital technologies in process management (blockchain, smart contacts, etc.) in the contour of the transport integrated management system allows to provide new opportunities for increasing the effectiveness of activities not only transport companies, but also all participants in the transport process.

The lack of stocks of finished products and high capital intensity of transportation lead to significant features in the structure of transport costs, where in addition to depreciation, the share of fuel costs is very high. In this regard, management's attention should also be directed to energy conservation and energy efficiency. From this point of view, lean production concept implies a constant effort to eliminate all types of losses, involve each employee in the business optimization process, and focus on the consumer as much as possible. Accordingly, transport management business processes require continuous improvement and quality improvement and should lead to lower costs and increased customer satisfaction. The process approach will also solve the problem of slow turnover of invested capital, accelerate the turnover of invested capital, and thus increase its profitability and ensure an increase in the market value of transport companies.

The implementation of the integrated management system should be carried out in the context of the risk management concept. High capital intensity and relatively low return on 
capital determine a priori a higher risk of creating value when implementing a growth strategy, the management of which necessitates the formation of requirements for profitability and quality of investments. Due to the high capital intensity, the activities of transport organizations are characterized by a high level of operational leverage and operational risk, as a result of which the influence of transport services market conditions in the implementation of the growth strategy is more significant. Taking into account the high sensitivity of the value of a transport company to a decrease in demand for transportation services, the requirements for the financial strength of the transport organization are increased. At the same time, the effect of the operating leverage is very high, which requires increasing the investment activity of the transport company with favorable prospects for economic growth. In general, a significant level of operational risk observed in transport requires the development of new approaches to the pricing of freight forwarding services. High capital intensity and low profitability of operating activities cause a long period of return on investment. This creates special requirements for the structure and cost of capital: there is a high need for long-term financing sources that are attracted for the payback period of investments. In this case, it is advisable to conduct a conservative or moderate financial policy, which implies a large share of their own funds. This makes it necessary to attract strategic investors in the transport industry who are interested in its long-term development and are ready for moderate risks and the average level of return on capital investments. The high demand of the transport industry for longterm sources of investment financing determines the relevance of initial and subsequent public offerings of shares by transport companies (IPO, SPO). By the way this contains a large growth potential, which will require effective management of the company's value in the future to increase the investment attractiveness and ensure economic growth of domestic transport organizations. The multiplier of profit and value growth is large and determines the choice of investment projects. Economic growth and value growth are linked by this multiplier. The uneven cash flow during the year due to the seasonality factor in Russia makes it necessary to reduce the company's operating and financial cycles and implement an effective credit policy.

The concept of stakeholders allows to manage the process of digitization of transport systems, taking into account the expectations of various stakeholders. Indicators for strategic controlling of the digital transformation of the transport system, in the form of balanced scorecard [19], from the position of expectations of the key stakeholders: state, business, social organizations and population, is given in [20].

\section{Discussion}

The main feature of the proposed approach is that the integrated management system, based on the use of digital technologies, allows to make rational management decisions, ensure increased efficiency and reduce the transport costs for producers. The focus of management is on achieving the set targets. In addition, the special role of digital technologies in the management of transport systems is emphasized as a key factor in realizing the competitive advantages of industrial enterprises, increasing the competitiveness of domestic products in the world market and achieving higher rates of economic growth.

The considered approach to creating an integrated management system for digital transformation in transport allows to solve the following tasks: to increase the efficiency of resource use; to provide a positive synergistic effect by reducing the cost of development and operation of the management system compared to the total cost of several autonomous management systems; to ensure consistency of actions of organizations in the transport industry, to increase the degree of their economic cooperation, and to eliminate duplication of functions; to create conditions for reducing conflicts between different management 
systems of the organizations through common policies, goals and objectives; to ensure continuous improvement of transport operations; to reduce management risks by ensuring that a single system takes into account the consequences of any action and the risks associated with it; to increase the satisfaction and well-being of customers, suppliers, investors and other stakeholders.

The proposed conceptual framework for building the integrated management system for improving efficiency of digitalization in transport forms the fundamental basis for further development of methodological provisions for creation and implementation of an organizational and economic mechanism in the management system of digital transformation in transport, taking into account industry specifics, economic development trend of consignors and new processes and phenomena of neoeconomics.

\section{Conclusions}

Summarizing the above reasoning, it can be concluded that effective implementation of the digital transformation processes in transport in order to reduce transport costs in the product price should be based on the complex conceptual approach. Digital transport systems should be formed on the integrated management platform, including the following concepts: Industry 4.0, sustainable development, process management, lean production, value-based management, the concepts of stakeholders, and risk management. The implementation of the above-mentioned conceptual approaches to digital transformation in transport within the framework of the integrated management system will improve information and technical support for the activities of transport organizations, which, in turn, will increase the efficiency and quality of transport services provided and reduce transport costs in the price of manufacturers' goods. The proposed integrated management system allows to make rational management decisions, ensure increased efficiency and reduce the transport costs for producers. As a result, domestic enterprises will get the competitive advantages on the world commodity market due to the opportunity of lowering prices and an increase in demand for their products. In general, this will help to raise foreign trade volumes by increasing exports of high-grade products and accelerate the country's socio-economic development.

Besides, planning of functioning of intellectual transport and logistical systems based on the proposed above integrated management system will allow to consider growth of tourist, industrial, scientific and technical potentials of territorial entity, develop forecast of business activity, stimulate economic and social growth by means of impact on expectations of the parties interested, while maximally using the degree of their support and feasibility to have impact of the main business processes that, as a result, will contribute to achieve the strategic goals set. While generating the digital frame of the national transport and logistical system, it is necessary to take into account its forthcoming integration into the global infrastructure. This will allow to create new opportunities for the population, business and state, strengthen the role of the country in the world transport and logistical and information and communication systems.

Further development of the subject may be associated with constructing mathematical models allowing to provide for the balance of interests of various groups of stakeholders when taking managerial decisions in the area of transport and logistics development, and also with integration of indices of digital transformation of transport and logistical system into a summary forecast model of socio-economic development of the country. 


\section{References}

1. Kommersant Homepage, https://www.kommersant.ru/doc/3019489

2. Program "Digital Economy of the Russian Federation": approved by the Order of the Government of the Russian Federation on July 28, 2017, 1632-r (2017)

3. Transport Strategy of the Russian Federation for the period up to 2030: approved by the Order of the Government of the Russian Federation on 2008/11/22, 1734-r (2008)

4. UNECE Transport Division, SINA, Intelligent Transport Systems (ITS) for sustainable mobility, https://www.unece.org/fileadmin/DAM/trans/publications/ Intelligent_Transport_Systems_for_Sustainable_Mobility.PDF

5. E. Balashova, I. Krasovskaya, E. Schislyaeva, F. Shamrai, IOP Conference Series: Materials Science and Engineering (2019) doi: 10.1088/1757-899X/497/1/012107

6. S. Barykin, O. Kalinina, E. Balchik, Innovative Management Neural Network Modelling Based on Logistic Theory. MATEC Web of Conferences (2018)

7. H. Dong, F. Hussain Computing 97(1), 79-102 (2013)doi: 10.1007/s00607-013-0347-8

8. M.G. Grigoryan, E.I. Alekhina, L.N. Buyanova, Development of Modern SocioEconomic Processes: State, Problems and Prospects (New Science, Petrozavodsk, Russia, 2019)

9. A.E. Kravchenko, D.A. Gura, Orbis 14, 35-45 (2018)

10. D.V. Kazunin, O.Ya. Timofeev, A.S. Ivanov, Morskoy Vestnik 3, 109-113 (2018)

11. L.V. Kokh, Yu.V. Kokh, V.S. Prosalova, Atlantis Highlights in Computer Sciences, Digital Technologies in Logistics and Infrastructure (ICDT-2019), 193-198 (2019)

12. M.N. Kripak, E.S. Palkina, Ya.A. Seliverstov, IOP Conf. Series: Materials Science and Engineering 709, 033065 (2020) doi:10.1088/1757-899X/709/3/033065

13. A.I. Levina, A.S. Dubgorn, O.Y. Iliashenko, Proceedings - 2017 European Conference on Electrical Engineering and Computer Science (EECS-2017), 351-355 (2018) DOI: 10.1109/EECS.2017.72

14. M. Lind, R. Watson, M. Bergmann, M. Rosemann, Digitizing the Maritime EcoSystem-Improving Door-to-door Coordination via a Digitized Transport Chain. STM (2018)

15. S. Ma, Economics of Maritime Business (2020) doi: 10.4324/9781315658124-16

16. S. Maydanova, I. Ilin, A. Lepekhin, Proceedings of the 33rd International Business Information Management Association Conference (IBIMA-2019), 5103-5111 (2019)

17. H. Rabbouch, F. Saâdaoui, M. Rafaa, Linking and Mining Heterogeneous and Multiview Data (2019) doi: 10.1007/978-3-030-01872-6_5

18. E. Schislyaeva et al, Actual Technologies of Modern Economy and Infrastructure: Digital and Innovation Economy (SMTU Publishing House, St. Petersburg, Russia, 2020)

19. R. Kaplan, D. Norton, The Balanced Scorecard: Translating Strategy into Action. Olimp-Business (Moscow, 2006)

20. E. Balashova, E. Palkina, E. Schislyaeva, International Conference on Digital Transformation in Logistics and Infrastructure (2019) doi: 10.2991/icdtli-19.2019.17 